\title{
Apoptosis-like death as a feature of malaria infection in mosquitoes
}

\author{
H. HURD*, K. M. GRANT and S. C. ARAMBAGE \\ Centre for Applied Entomology and Parasitology, Institute for Science and Technology in Medicine, University of Keele, \\ Staffordshire, ST5 5BG, UK
}

\begin{abstract}
S U M MAR Y
Malaria parasites of the genus Plasmodium make a hazardous journey through their mosquito vectors. The majority die in the process, many as a result of the action of mosquito defence mechanisms. The mosquito too is not unscathed by the encounter with these parasites. Tissue damage occurs as a result of mid-gut invasion and reproductive fitness is lost when many developing ovarian follicles are resorbed. Here we discuss some of the mechanisms that are involved in killing the parasite and in the self-defence mechanisms employed by the mosquito to repair the mid-gut epithelium and to manipulate resources altering the trade-off position that balances reproduction and survival. In all cases, cells die by apoptotic-like mechanisms. In the midgut cells, apoptosis-induction pathways are being elucidated, the molecules involved in apoptosis are being recognised and Drosophila homologues sought. The death of ookinetes in the mosquito mid-gut lumen is associated with caspase-like activity and, although homologues of mammalian caspases are not present in the malaria genome, other cysteine proteases that are potential candidates have been discussed. In the ovary, apoptosis of patches of follicular epithelial cells is followed by resorption of the developing follicle and a subsequent loss of egg production in that follicle.
\end{abstract}

Key words: Apoptosis, Plasmodium, malaria, mosquito cysteine proteases.

\section{INTRODUCTION}

Mosquitoes play an essential role in the transmission and spread of malaria. If a female mosquito ingests blood containing Plasmodium gametocytes, the male and female gametes emerge from their erythrocytes within minutes of arriving in the mosquito midgut lumen and fertilization occurs within the first hour post-feeding. The zygote differentiates into a motile ookinete 8-24 hours later, moves out of the blood bolus and migrates across the peritrophic matrix, a chitin-containing layer secreted by the midgut epithelial cells in response to blood feeding. Ookinetes invade the single layer of columnar midgut epithelial cells, often travelling laterally through one or more adjacent cells, and finally exit on the basal side of the cells, coming to rest between the cell membrane and the basal lamina in the basal subepithelial space. Here they transform into a non-motile vegetative stage, the oocyst. The oocyst grows from about 5 to $50 \mu \mathrm{m}$ in diameter whilst the nucleus divides approximately once a day to produce 2-8000 nuclei in 12-18 days. Following division of the cytoplasm, sporozoites develop at the edge of the oocyst and are eventually released into the haemolymph. A small proportion of these invade the lateral lobes of the

* Corresponding author: Centre for Applied Entomology and Parasitology, Institute for Science and Technology in Medicine, University of Keele, Staffordshire, ST5 5BG, UK. Tel: +44 1782 583034. Fax: +44 1782583516 . Email: h.hurd@keele.ac.uk salivary glands. Eventually a small number of sporozoites are injected into a new host when the infected mosquito takes the next blood meal (Sinden, 2002; Baton and Ranford-Cartwright, $2005 b$ ).

Although several species of Plasmodium can readily be maintained in laboratory colonies of mosquitoes, several factors mitigate against the successful completion of the mosquito stage of the life cycle in the field. Plasmodium has a surprisingly long developmental period relative to the life expectation of a mosquito in the wild, and many infected mosquitoes will die before sporozoites have invaded the salivary glands. Furthermore, the few mosquito species that can act as vectors of Plasmodium have robust anti-parasite defence mechanisms; although these are more effective in some vector/parasite combinations than others. Mosquitoes thus exhibit varying degrees of refractoriness and this will determine prevalence and/or intensity of infection within a mosquito population (Ghosh, Edwards and Jacobs-Lorena, 2000; Sinden, Alavi and Raine, 2004). Our understanding of these defence mechanisms is expanding rapidly and has been the subject of many reviews including recent ones by Michel and Kafatos (2005) and Vlachou and Kafatos (2005).

The most significant loss of malaria parasites occurs in the first $24 \mathrm{~h}$ following an infective blood meal. This also appears to be a critical time for the infected mosquito. During this period, infection inflicts considerable fitness costs upon the mosquito because ookinete invasion of mosquito-midgut cells 
results in cell death and expulsion from the epithelial layer. The production of a batch of eggs that is taking place at this time is severely impaired due to the death of cells in the follicular epithelium of many ovarioles. It is clear that the complex molecular interactions between Plasmodium and its vector that occur at this time help to establish and maintain the infection and may ensure that the vector remains alive for long enough for sporozoites to develop and parasite transmission to occur. Evolutionary pressures will be operating upon the mosquito resulting in selection in favour of survival following infection. They will also be operating on the parasite to maximise its fitness without compromising vector survival; at least until transmission is ensured. We have proposed that death of parasite and vector cells plays a key role in this relationship (Hurd and Carter, 2004). In this review we discuss the mode of death of parasite and vector cells, potential triggers that induce this death and the role this death may have in the maintenance of the infection.

MOSQUITO DEFENCE RESPONSES

AGAINST MALARIA

A complex anti-parasite response is mounted by the mosquito within $24 \mathrm{~h}$ of taking a Plasmodiuminfected blood meal. Several defence molecules have already been implicated in this response, including antimicrobial peptides, host pattern recognition receptors (PRRs) such as peptidoglycan recognition proteins, Gram-negative binding proteins, thioester containing proteins (TEPs), scavenger receptors (SCRs), C-type lectins (CTLs) and molecules in the melanisation cascade (Michel and Kafatos, 2005). The genes encoding some of these molecules exhibit transcriptional activation or up-regulation in response to Plasmodium infection (Richman et al. 1997; Dimopoulos, 2003; Danielli et al. 2005) and a few have now been implicated in parasite-killing or protection from death, as demonstrated by the change in oocyst numbers when gene expression is altered (Blandin and Levashina, 2004; Osta et al. 2004b; Abraham et al. 2005).

Attention has been focused on the death of ookinetes as they traverse the midgut epithelium and exit beneath the basal lamina. Two processes have been reported to occur, namely, melanisation and 'lysis' of ookinetes. In a few strains of mosquito, specifically selected to be refractory, ookinetes are melanised as they emerge from epithelial cells and come into contact with molecules in the haemolymph (Collins et al. 1986; Zheng et al. 2003; Hurd et al. 2006). However, it would appear that, even in susceptible mosquitoes, many parasites disappear before oocyst formation. This disappearance mechanisms has been termed 'lysis', though cell lysis is rarely visualized, and is likely to be mediated by the antagonistic action of the leucine rich-repeat immune gene, LRIM1 (Osta et al. 2004a). These parasites can be protected from death by a mechanism mediated by 2 members of the C-type lectin family (Osta et al. 2004a). Ookinetes undergoing lysis have been observed in mid-gut cells of a refractory line of Aedes aegypti (Vernick et al. 1995). However, this has not been observed in the midgut epithelium of anopheline mosquitoes and it is not clear whether disappearance of parasites in Anopheles gambiae occurs in the epithelial cells or, prior to invasion, in the mid-gut lumen.

THE MID-GUT LUMEN IS A HOSTILE

ENVIRONMENT

In addition to the response mounted against the parasite by the mosquito, toxic components from the blood meal surround the developing ookinetes. Within the bolus of the blood meal, zygotes and ookinetes are directly exposed to white blood cell products and also serum and plasma factors. All of these reduce gametocyte infectivity (Lensen et al. 1998). A reactive oxygen-rich environment is created, partly as a result of the release of oxidative haem when haemoglobin is digested. The mid-gut environment may, in this respect, resemble the situation surrounding developing trophozoites in the vertebrate host (Atamna and Ginsburg, 1993). The cytotoxic effect of $\mathrm{O}_{2}^{-}$upon Plasmodium berghei has been reported and $\mathrm{O}_{2}^{-}$has been implicated in loss of gametocyte infectivity (Harada et al. 2001). In addition to the generation of $\mathrm{O}_{2}^{-}$by haemoactivity within the mid-gut lumen, L-DOPA-dependent generation of $\mathrm{O}_{2}^{-}$occurs in the mid-gut epithelium and it is suggested that parasite invasion may induce transportation of L-DOPA from the haemolymph into mid-gut epithelial cells (Lanz-Mendoza et al. 2002). The latter authors reported that P. berghei ookinetes differ in their susceptibility to $\mathrm{O}_{2}^{-}$. Interestingly, the identification of peroxidase active organelles in the trophozoites of $P$. falciparum suggests the presence of antioxidant defensive mechanisms in Plasmodium. However, database searches of the $P$. falciparum genome failed to identify genes encoding peroxisomal enzymes or the classical peroxisomal import systems (McIntosh, Elliott and Joiner, 2005). In contrast, cytosolic redox systems that protect against oxidative insults resulting from the asexual stage's metabolism of haemoglobin are well documented and reviewed in Muller (2004) and a potential antioxidant, lipoic acid, that may be synthesised by the apicomplast could also be utilized as an antioxidant by the parasite (Toler, 2005).

\section{NITRIC OXIDE}

One molecule that has been particularly implicated in the killing of Plasmodium is nitric oxide (NO). 
Inducible $\mathrm{NO}$ is synthesised during the oxidation of L-alanine to L-citrulline; catalysed by inducible NO-synthase enzymes (iNOS). NO rapidly forms reactive nitrogen intermediates (RNIs).

NO has long been known to be an anti-pathogen agent, although its pleiotrophic effects are dependent upon its concentration, location and reaction with superoxide. The complex relationship between $\mathrm{NO}$ and $P$. falciparum infections in the vertebrate host is still unresolved (Clark, Rockett and Burgner, 2003). It is likely that the bioavailability of NO in the vasculature of malaria-infected hosts is low, due to NO scavenging by haemoglobin and $\mathrm{O}_{2}^{-}$, and there is evidence that $\mathrm{NO}$ does not have a killing effect on rodent-malaria (reviewed in Sobolewski et al. 2005) although this conclusion is controversial (Balmer et al. 2000). It appears that NO-derived products such as nitrosothiols, rather than NO itself, are toxic to the parasite (Rockett et al. 1991).

The situation in the insect midgut lumen may, however, be different compared with that in the vertebrate. Several workers have demonstrated that RNIs reduce malaria transmission by affecting gametocyte infectivity, and this inactivation has been associated with the presence of white blood cells (Motard et al. 1993; Naotunne et al. 1993). Furthermore the killing effect of NO on ookinetes has been demonstrated by trypan blue staining (Herrera-Ortiz et al. 2004).

In addition to $\mathrm{NO}$ generated within the blood meal, the expression of an inducible form of the A. stephensi NOS gene $(A s N O S)$ has been shown to increase transiently in $P$. berghei-infected mosquitoes. Dietary provision of the NOS substrate, L-arginine, or a NOS inhibitor, L-NAME, reduced or increased oocyst numbers in infected mosquitoes, respectively; demonstrating that parasite numbers are limited by NO (Luckhart et al. 1998). P. bergheiinfected blood meals also induce iNOS in the midguts of $A$.pseudopunctipennis, as does L-DOPA; indicating the participation of $\mathrm{H}_{2} \mathrm{O}_{2}$ (Herrera-Ortiz et al. 2004). P. falciparum has been shown to induce expression of $A s N O S$ as early as $6 \mathrm{~h}$ post-infection (Crampton and Luckhart, 2001; Lim et al. 2005).

There is evidence to support the proposition that one inducer of AsNOS expression is an immunomodulatory cytokine from the host, namely mammalian transforming growth factor $\beta 1$ (TGF $\beta 1$ ). This factor plays a role in regulating inducible NOS in vertebrates. TGF $\beta 1$ is present in the blood in an inactive form and is activated in the midgut lumen, probably by haem or the redox product of NO, nitroxyl anion. It significantly reduces the number of $P$. falciparum oocysts developing on the midgut wall and induces NOS expression in an A. stephensi cell line (Luckhart et al. 2003). Interestingly, a member of the $\mathrm{TGF} \beta$ super-family, As60A, has been isolated from A. stephensi and is expressed in the midgut, brain, eyes, fat body and ovaries. In the mosquito carcass, induction of $A s 60 A$ was detected $1 \mathrm{~h}$ after an infected blood meal, earlier than the induction seen at $3 \mathrm{~h}$ in the midgut. The expression of both $A s 60 A$ and $A s N O S$ appears to be correlated with the intensity of parasite density, with high densities inducing expression and low densities suppressing it (Crampton and Luckhart, 2001).

There now appears to be a third source of NOS inducers: the parasite itself. Luckhart and colleagues have shown that the glycosylphosphatidylinositol (PfGPI) anchors of $P$. falciparum also induce AsNOS expression in midgut epithelial cells. Within the gut lumen PfGPIs could be derived from both sexual and asexual stages of Plasmodium. Merozoites act upon an Anopheles stephensi cell line to induce NOS expression in a dose-dependent manner, as do purified PfGPIs (Lim et al. 2005). This is in line with other studies showing that vertebrate-host proinflammatory cytokines and $\mathrm{NO}$ can be induced by parasite GPIs, and may be major factors that contribute to malaria pathogenesis (Tachado et al. 1996; Zhu, Krishnegowda and Gowda, 2005).

\section{PARASITE DEATH}

Oxygen radicals, nitric oxide and reactive nitrogen intermediates (RNIs) are known inducers of programmed cell death or apoptosis (Murphy, 1999; Bai et al. 2001) as discussed in Hurd and Carter (2004). There is evidence that $\mathrm{H}_{2} \mathrm{O}_{2}$ causes the death of $P$. berghei ookinetes (Herrera-Ortiz et al. 2004) but it is unclear whether this death equates to the apoptotic-like death observed in ookinetes in vivo and in vitro (Al-Olayan, Williams and Hurd, 2002). However, what is certain is that very few of the thousands of mosquito stages that begin their development in this hostile environment survive to become oocysts (Vaughan, Hensley and Beier, $1994 a$; Vaughan, Noden and Beier, 1994b; Alavi et al. 2003). Data for the reduction in numbers of $P$. falciparum, $P$. yoelii and $P$. vivax as they pass through different stages in development has been tabulated in Ghosh et al. (2000). These figures reflect large differences in the successful survival of the parasite in different malaria/mosquito species combinations, with losses ranging from 40 - to 1223 -fold at the gametocyte to ookinete stage and 69- to 660fold from ookinetes to oocysts. This latter loss is usually detected by counting ookinetes in the midgut lumen of a cohort of mosquitoes and then examining the midguts of a further group of mosquitoes for the presence of oocysts several days later. Although it has been assumed that this loss occurs during the transit of the midgut epithelial layer (Whitten, Shiao and Levashina, 2006), there is evidence that a large proportion of ookinetes die whilst still in the midgut lumen, and that this death rate increases the longer they are exposed to the increasingly toxic 
environment (Al-Olayan et al. 2002). It is feasible that $\mathrm{NO}$ and/or RNIs and $\mathrm{O}_{2}^{-}$are the triggers that induce ookinete death. We propose that parasites die in the midgut lumen by a process of apoptosis and that this may be equivalent to the 'lysis' discussed by many authors.

INDICATORS OF APOPTOSIS - LIKE CELL

DEATH IN PLASMODIUM

Apoptosis in Plasmodium spp. was first demonstrated when one marker of apoptosis, nuclear chromatin fragmentation, was detected in the erythrocytic stages of chloroquine-sensitive $P$. falciparum which had been exposed to the drug in vitro (Picot et al. 1997). More recent work has reported that apoptosis can be detected in both stressed cultures and untreated healthy cultures of erythrocytic stages (Deponte and Becker, 2004). However, there was significant increase in the in situ terminal-deoxynucleotidyl-transferase-mediated dUTP-biotin nick end labeling (TUNEL)-positive apoptotic schizonts treated with anti-malarials and $\mathrm{H}_{2} \mathrm{O}_{2}$, compared to the control (Deponte and Becker, 2004). Results of further experiments, conducted by these authors, to demonstrate externalization of phosphatidylserine from the inner to the outer leaflet of the parasite plasma membrane were confounded by the two additional membranes, the parasitophorous vacuole membrane and the erythrocyte membrane, that surround the parasite plasma membrane. Contamination of the parasite preparation with erythrocyte ghosts may have led to false-positive staining with annexin $\mathrm{V}$.

Multiple features of apoptosis, such as chromatin condensation, detected with acridine orange labeling; DNA fragmentation, as detected by TUNEL labeling; phosphatidylserine translocated to the external leaflet of the plasma membrane, as detected by annexin labeling; and activation of a caspaselike enzyme activity (Fig. 1) have been observed in $P$. berghei ookinetes. Apoptosis occurs both in vivo, in the mosquito gut lumen, and in vitro (Al-Olayan et al. 2002). Apoptosis in P. berghei was inhibited by the general caspase inhibitors, $z-V A D$.fmk and Boc-ASP, and the caspase 3-specific inhibitor, z-DEVD.fmk, thus confirming the involvement of caspase-like activity in cell death in Plasmodium. In vitro, the presence of ookinetes exhibiting condensed chromatin was reduced from $80 \%$ to less than $10 \%$ by incubation with the caspase inhibitor z-DEVD.fmk and, in vivo, addition of z-VAD.fmk to the blood meal resulted in a reduction in the number of ookinetes exhibiting condensed chromatin from approximately $70 \%$ to $20 \%$. Moreover, inclusion of a caspase inhibitor in the blood meal resulted in double the number of oocysts developing on the midgut wall in vivo, suggesting that apoptosis plays a major role in the mechanism that governs parasite
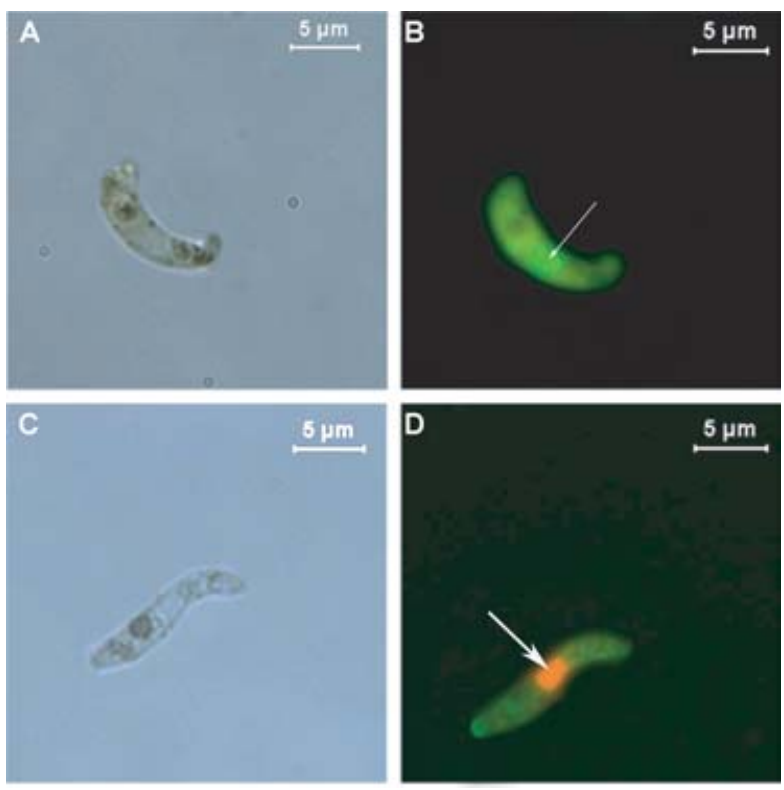

Fig. 1. Plasmodium berghei ookinetes exhibiting features of apoptosis-like cell death. A: ookinete viewed under phase contrast, B: the same ookinete viewed under conditions that show staining with acridine orange and containing a nucleus with condensed chromatin (thin arrow). C: ookinete viewed under phase contrast, D: the same ookinete viewed under conditions that show caspase-like activity in the cytoplasm after labelling with CaspaTag $^{\text {TM }}$ (Intergen Company) (green). The nucleus is stained with Hoechst stain (thick arrow).

numbers in the mosquito midgut lumen (Al-Olayan et al. 2002). The involvement of caspase-like activity must, however, be interpreted with caution, as Deponte and Becker (2004) pointed out, since nothing is known about uptake and stability of caspase inhibitors in P. falciparum.

\section{CASPASE-LIKE ACTIVITY}

In $P$. berghei, two different methods employing caspase-specific inhibitors have been used to detect a caspase-like enzyme in ookinetes: (1) whole cells were labeled with a fluorescently labeled caspase inhibitor (CaspaTag, a carboxyfluorescein-labeled fluoromethyl ketone peptide inhibitor, FAM-VADfmk) (Fig. 1). This labeling correlates well with another marker for apoptosis, chromatin condensation (as visualized by acridine orange staining) (Fig. 1). (2) Ookinete cell extracts were incubated with a biotinylated caspase inhibitor (biotin-VAD. fmk) and the proteins which bound the inhibitor were subsequently visualized on a Western blot (Al-Olayan et al. 2002).

Therefore, $P$. berghei appears to possess a caspaselike activity that correlates with other markers of apoptosis. However, interrogation of the genome databases of $P$. berghei and the closely related $P$. falciparum, reveals that Plasmodium does not appear to possess a classical caspase enzyme. 

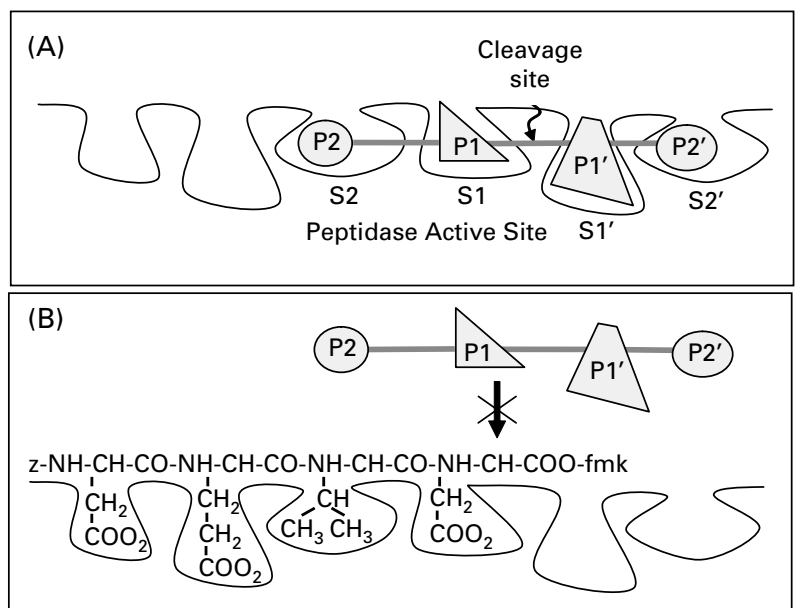

Fig. 2. Diagrammatic representation of the active site of a protease enzyme. (A) $\mathrm{P} 1, \mathrm{P} 2, \mathrm{P} 1^{\prime}$ and $\mathrm{P} 2{ }^{\prime}$ refer to amino acid residues in the protein/peptide substrate relative to the cleavage site. $\mathrm{S} 1, \mathrm{~S} 2, \mathrm{~S}^{\prime}$ and $\mathrm{S} 2^{\prime}$ refer to the sub-sites within the active site of the enzyme. These bind amino acid residues in the protein or peptide substrate with different affinities and thus confer the specificity of the proteolysis. (B) protease inhibitors, such as z-DEVD-fmk, bind irreversibly into the active site and prevent binding of the substrate.

This calls into the question the true intracellular target of the 'caspase-specific' inhibitors.

Caspases are cysteine proteases belonging to the clan CD (Barrett and Rawlings, 2001). They possess a conserved caspase fold and a catalytic dyad, His and Cys, which are indispensable for proteolytic activity. One of the main limitations of working with caspase inhibitors is that their specificity is not as tight as once believed. These inhibitors do demonstrate remarkable specificity in vitro but this specificity is not maintained in cell-based assays (Rozman-Pungercar et al. 2003). This may be due to the irreversible nature of the inhibitor: nonoptimal inhibitors may still bind weakly to the active site and, once bound, they will become covalently linked to the enzyme. The longer the incubation period, the greater chance there is that an inhibitor will become irreversibly attached to a non-optimal protease target. Moreover, many of these peptidebased inhibitors are not cell permeable and, to overcome this problem, ester-derivatives (where the aspartic acid of, for example, z-VAD, has been esterified) are commonly used in cell-based assays. Once in the cell, esterases are thought to remove the ester group, releasing the active inhibitor. However, the ester-derivatives lack the specificity of the free acid peptide inhibitors, thus confounding the situation further.

The peptide-based inhibitors act by mimicking the substrate and binding into the catalytic site (Fig. 2). Caspases have an absolute requirement for a single amino acid residue at $\mathrm{P} 1$ and exclusively hydrolyse the peptide bond following an aspartic acid residue; the residue at the $\mathrm{P} 4$ position is also a critical determinant of specificity (Thornberry, 1997; Thornberry et al. 1997). However, many of the inhibitors designed to fulfill these criteria, for example $z$-VAD and $z$-DEVD, also fulfill the specificity determinants for cysteine proteases of a different clan, CA. Clan CA, which includes the lysosomal cathepsins and the calcium-dependent calpains, prefer a hydrophobic or large residue at $\mathrm{P} 2$ but have no preference for the $\mathrm{P} 1$ residue (Mottram et al. 2003). Hence, the alanine in z-VAD and the valine in $z$-DEVD, comply with clan CA requirements and these inhibitors have indeed been shown to inhibit cathepsin B, another clan CA protease (Rozman-Pungercar et al. 2003).

\section{Metacaspase}

So, if Plasmodium lacks true caspases, what other proteases could represent the target for the caspase inhibitors? One possible alternative is the recently discovered metacaspase proteins, another clan CD protease, which are distantly related to caspases. Metacaspases represent one of two families of ancient caspase-like proteins (paracaspases and metacaspases) which have been identified recently in metazoans (including humans), fungi and Protozoa (Uren et al. 2000). Based on evaluation of the $P$. falciparum genome sequence, this parasite appears to possess two metacaspases, although neither have been characterized or shown to be enzymatically active (Rosenthal, 2004). P. berghei has also been shown to possess two metacaspases genes to date (GenBank, accession numbers AJ555625 and AJ555626). Alignment of the Plasmodium metacaspases with caspases reveals that they retain the typical caspase fold and the catalytic dyad (His, Cys) required for catalytic activity but there is considerable sequence diversity in the vicinity of the active site cleft, which may indicate a difference in substrate specificity (Wu et al. 2003). Moreover, aspartic aciddirected processing sites in metacaspases cannot be predicted from homology with the caspases, implying that they are not processed in a similar manner (Mottram et al. 2003).

Phylogenetic analysis suggests that the metacaspases belong to a distinct clade which may represent the evolutionary progenitor of mammalian caspases (Mottram et al. 2003). In support of this theory is the fact that the yeast metacaspase has been shown to regulate programmed cell death in this unicellular organism (Madeo et al. 2002; Mazzoni et al. 2005). Induction of apoptosis is accompanied by an increase in a protease activity which cleaves caspase-specific substrates. Apoptosis is abrogated in metacaspase null mutants and is exacerbated in yeast which over-express the metacaspase. The yeast metacaspase can also be inhibited by z-VAD (Madeo et al. 2002). 


\section{Calpain}

Another possible target for caspase inhibitors in Plasmodium is the calpains, cytosolic calciumdependent cysteine proteases. Calpains are clan CA cysteine proteases but can be inhibited by caspase inhibitors such as z-VAD (Waterhouse et al. 1998). Calpains have been implicated in apoptosis in mammalian cells (Squier and Cohen, 1997) and are thought to be involved in both caspase-dependent (Nakagawa and Yuan, 2000; Blomgren et al. 2001) and caspase-independent pathways (Wolf et al. 1999). Moreover, calpain inhibitors have been shown to inhibit apoptosis in neuronal cells (Squier et al. 1994; Blomgren et al. 2001). Calpains may act in multiple ways: cleaving and activating effector caspases, cleaving caspase targets to potentiate their effects and disturbing calcium homeostasis and hence trigger apoptosis (Nakagawa and Yuan, 2000; Blomgren et al. 2001).

Database mining of the $P$. falciparum genome sequence has identified two putative calpain homologues in this parasite (Wu et al. 2003). They possess a catalytic domain with three active sites, which together constitute the catalytic cleft, but lack a calcium-binding domain, suggesting that the malarial calpains are calcium independent (Wu et al. 2003).

\section{Cathepsins}

Finally, the caspase inhibitors could be targeting lysosomal cysteine proteases, cathepsin L-like enzymes, of which Plasmodium has many, including the falcipains (or berghipains in $P$. berghei) and the SERAs (Wu et al. 2003; Rosenthal, 2004). In mammalian cells, lysosomal proteases have been implicated in apoptosis: some are thought to act indirectly by activating caspases (Turk et al. 2002); some are thought to act directly on apoptosis substrates (Stoka et al. 2001 ; Turk et al. 2002) and others have proposed that lysosomal proteases elicit programmed cell death through an alternative pathway, autophagy (Bursch, 2001).

The most characterized cathepsin L-like enzymes in Plasmodium are the falcipains. P. falciparum has four falcipain orthologues, falcipain $1,2,2^{\prime}$ and 3 (Rosenthal, 2004). Falcipain 2 and 3 are involved in haemoglobin hydrolysis in the erythrocytic stages of the parasite (Rosenthal, 1995; Gamboa de Dominguez and Rosenthal, 1996; Rosenthal et al. 1996), but this does not preclude them having a distinct role in the insect stages. Falcipain 1 is thought to play a role in oocyst development (Eksi et al. 2004). Falcipain 1 null mutant parasites were viable and normal in the erythrocytic stages, gametocytes and gametes but produced 70-90\% less oocysts when fed to mosquitoes. However, it is not clear when falcipain 1 acts during oocyst development: its transcription escalates dramatically in gametocytes and gametes but falcipain 1 knockout mutants are morphologically normal at these stages (Eksi et al. 2004), raising the possibility that falcipain 1 acts during the intervening stage, the ookinete. Genes encoding falcipain homologues in other plasmodial species, including $P$. berghei, have been identified (Rosenthal et al. 2002). P. berghei has one falcipain 1 homologue and one falcipain $2 / 3$ homologue. The falcipains are expressed to different extents in different life cycle stages of the malaria parasite (Le Roch et al. 2003) but no data exists for their expression in the ookinete or oocyst stages.

Another group of abundant cathepsin L-like cysteine proteases in Plasmodium, are the serinerepeat antigen or SERA proteins (Rosenthal, 2004). There are nine SERA protease genes, eight of which are located in an array on chromosome 2 and another single gene on chromosome 9 of $P$. falciparum. The SERA genes are expressed throughout the parasite's life cycle: in rings (SERA1), trophozoites (SERA2, 3 and 9), schizonts (SERA2-9), merozoites (apart from SERA8), gametocytes (SERA1, 2, 4, 6, 7 and 9) and sporozoites (apart from SERA3 and 5) (Miller et al. 2002; Bozdech et al. 2003; LeRoch et al. 2003). No data exists for the expression of SERA genes in ookinetes. In erythrocytic stages, despite all 9 genes being expressed, only SERAs4-7 could be detected at the protein level (Miller et al. 2002). SERA5 is the most abundant and has been implicated in parasite egress and/or erythrocyte invasion (Pang, Mitamura and Horii, 1999).

All SERA proteins contain a central domain with strong homology to papain-family cysteine proteases but several SERAs, including the abundant SERA5, have a serine residue in place of the active site cysteine (Kiefer et al. 1996; Gor et al. 1998; Hodder et al. 2003) which will undoubtedly influence the substrate specificity and inhibitor sensitivity. For example, SERA5 possesses a chymotrypsin-like protease activity, with a $\mathrm{P} 1$ specificity for an aromatic amino acid, which can be inhibited by a serine protease inhibitor (Hodder et al. 2003). Thus it is extremely unlikely that SERA5, and perhaps the other SERAs with active site serines, would be inhibited by the caspase inhibitors.

More detailed inhibitor studies are required, using inhibitors which can differentiate between the different potential candidates, to be able to ascertain which of these potential proteases could be the caspase-like enzyme in apoptotic ookinetes. The classical clan CA protease inhibitor, $L$-trans epoxysuccinyl-leucylamido-(4-guanidino)-butane or E64, will only inhibit the lysosomal cysteine proteases, although recent studies suggest that falcipain 1 may be insensitive to this inhibitor (Goh, Goh and Sim, 2005). Alternatively, tripeptide aldehyde inhibitors, such as antipain, could be used to inhibit the lysosomal cysteine proteases. Calpain inhibitors, such 
as Z-LLY-FMK, also exist, and may be useful in eliminating these candidates.

Genome mining of the completed P. falciparum database unearths very few genes encoding for proteins involved in apoptosis. Not only are caspases missing but their downstream substrates, such as $\mathrm{Bcl}$ proteins, are also absent. Thus it appears that, although Plasmodium undergoes a form of cell death which resembles apoptosis, where the end results are conserved (chromatin condensation, DNA fragmentation etc.), the pathways are not the same as mammalian cells. Since Plasmodium possesses a metacaspase, which is thought to be the ancestral progenitor of the mammalian caspases (Wu et al. 2003), it suggests that higher eukaryotes have evolved and elaborated the caspase pathways in a very different manner from protozoa.

\section{Timing of events}

Markers of apoptosis are good indicators to study the onset of cell death and the sequence of events in the apoptotic pathway. Al-Olayan et al. (2002) studied the increase in the number of dying ookinetes in a population by detecting nuclear chromatin condensation. According to their results, apoptotic ookinetes were first observed at $12 \mathrm{~h}$ post-culture of gametocytaemic blood, and the proportion undergoing apoptosis increased up to $31 \%$ and $80 \%$ at $24 \mathrm{~h}$ and $36 \mathrm{~h}$ respectively. We studied the sequence of occurrence of two apoptotic markers, nuclear condensation and activation of caspase-like molecules, between $18 \mathrm{~h}$ to $26 \mathrm{~h}$ post-culture. A significant and increasing proportion of ookinetes become labelled with CaspaTag (FAM-VAD.fmk) from $18-26 \mathrm{~h}$ post culture of gametocytaemic blood onwards and this labelling correlates well with another marker for apoptosis, acridine orange labelling. Dead cells were detected by propidium iodide staining, identifying cells with compromised membranes, and were detected from $20 \mathrm{~h}$ onwards. The proportion of dead cells increased slowly with time but was significantly lower than ookinetes demonstrating markers of apoptosis (unpublished observations).

Temporal profiles of apoptosis-like cell death have yet to be performed in vivo. The observations made in vitro may not be comparable with the situation in vivo, where live ookinetes rapidly escape from their toxic environment as they invade the midgut, with the total numbers of ookinetes per midgut falling rapidly from 18-24 h post-feeding (Al-Olayan et al. 2002). At $18 \mathrm{~h}$, a much higher proportion of ookinetes exhibit signs of apoptosis-like death in vivo than in vitro, suggesting that the triggers which induce apoptosis are more potent in the mosquito than in our culture conditions. By $24 \mathrm{~h}$, however, the proportion of dying ookinetes in culture has reached similar levels to those in the midgut lumen. This equalization of the proportion of dying cells may simply reflect the escape from the gut lumen of healthy parasites in vivo. We do not know how rapidly apoptosis-like cell death progresses in $P$. berghei. Ookinetes labelled with fluorochrome indicators of apoptosis appear normal when viewed under white light, their membrane permeability may be unaffected for several hours and they may even be capable of the gliding motility necessary for movement out of the blood bolus and cell invasion.

OOKINETE-INDUCED APOPTOSIS IN THE

MID-GUT EPITHELIUM

During their passage out of the hostile environment of the mid-gut, ookinetes must traverse the monolayer of midgut epithelial cells. The route of their passage has been controversial. Observations of various malaria parasite/host combinations have generated hypotheses suggesting exclusively intracellular, exclusively intercellular or both routes. This debate has been reviewed recently (Baton and Ranford-Cartwright, 2004, 2005 a) and will not be discussed in detail here, other than to observe that there now appears to be a consensus supporting the view that ookinetes do invade the epithelial cells rather than pass between them (Han et al. 2000; Zieler and Dvorak, 2000; Vlachou et al. 2004) though Levashina and co-workers (Whitten et al. 2006) report a much higher proportion of $P$. berghei ookinetes in extracellular spaces than intercellular.

What is also now clear is that, in several malaria parasite/vector permutations, transit through the cells causes damage. Invaded midgut epithelial cells rapidly exhibit morphological changes including loss of microvilli, nuclear pyknosis, surface blebbing and decrease in refractive index (reviewed in Hurd and Carter (2004) and Hurd, Carter and Nacer (2005). Invaded cells are extruded from the epithelial layer into the gut lumen.

\section{The time-bomb theory}

Ookinetes rapidly move laterally away from the toxic environment of the dying cell, often invading several cells before moving out of the epithelium and into the basal subepithelial space. This lateral invasion has been observed by video microscopy in vivo in $P$. gallinaceum-infected $A$. aegypti (Zieler and Dvorak, 2000) and by time confocal microscopy of $P$. berghei infection in both $A$. stephensi and $A$. gambiae (Vlachou et al. 2004). Han and co-workers coined the phrase 'time-bomb theory' to describe their hypothesis that the invading ookinetes trigger epithelial cell destruction (detonate a bomb) from which they must rapidly escape if they are to survive (Han et al. 2000; Han and Barillas-Mury, 2002; Baton and Ranford-Cartwright, 2004). They observed that $95 \%$ of the invading parasites escape 
unharmed from the dying cells and suggested that the majority of parasite losses occur before the ookinete invades the epithelium or after the oocyst is formed. Invasion of additional cells may be dependent upon the speed at which invaded cells are extruded and Baton and Ranford-Cartwright (2005a) have proposed that rapid extrusion of invaded cells results in a cellular treadmill whereby ookinetes move from one cell to an adjacent one as the first cell is pushed out of the epithelial layer.

Vlachou et al. (2004) observed the cells surrounding the invaded cell undergoing extensive lamellipodia crawling to fill in the gap in the epithelial barrier caused by loss of the damaged cell. Invaded cells produced a 'hood' of lamellipodia that surrounds the ookinete as it exits the epithelial cell. These observations supplement the proposal of Han et al. that expulsion of invaded cells from the epithelial layer may be aided by a purse-string contraction of a basal actin ring in the damaged cell, although the method of cell extrusion may vary between different mosquito species (Gupta et al. 2005).

In addition to the GPI-anchored surface protein P28, ookinetes secrete a subtilisin-like serine protease, $\mathrm{PbSub} 2$, into the cytoplasm of invaded cells and this forms protein aggregates, often associated with the actin cytoskeleton (Han et al. 2000; Han and Barillas-Mury, 2002). The putative involvement of these parasite molecules in triggering up-regulation of midgut NOS and/or midgut cell apoptosis has yet to be investigated.

\section{Apoptosis of mid-gut cells}

Mid-gut epithelial cells that have been invaded by ookinetes are undergoing apoptosis as they protrude into the mid-gut lumen and are budded off. DNA fragmentation has been detected by TUNEL (Han et al. 2000). The apoptotic death of invaded cells was also revealed using Yo-PRO-1 staining as the dye passes selectively through the plasma membranes of apoptotic cells. In contrast, propidium iodide was excluded, ruling out necrotic cell death (Vlachou et al. 2004). Furthermore, caspase-like activity was detected in the invaded midgut cells of $P$. gallinaceum infected $A e$. aegypti by preloading cells with the cell-permeable protease substrate PhilPhilLux- $\mathrm{G}_{1} \mathrm{D}_{2}$ prior to invasion (Zieler and Dvorak, 2000).

Biochemical events occurring in $P$. bergheiinvaded mid-gut cells have been investigated by the group of Barillas-Mury (Han et al. 2000). Using immunofluorescence staining with antibodies raised against the ookinete surface molecule, P28, and a universal anti-NOS rabbit polyclonal, they were able to co-localise the parasite with NOS expressing mid-gut cells. They also demonstrated the A. gambiae transcription factor AgSTAT was expressed very weakly in the cytoplasm and not at all in the nuclei of invaded cells. Epithelial cells protruding into the mid-gut lumen had lower levels of AgSTAT and their nuclei were TUNEL positive. This group propose that cell invasion causes physical damage and molecular changes that ultimately lead to death by apoptosis (Han et al. 2000).

\section{Biochemical reactions that may initiate apoptosis}

As discussed above, several authors have reported that, following Plasmodium infection, a generalized up-regulation of the NOS gene occurs in the gut that may be induced by a combination of mammalian, parasite and mosquito factors. Our understanding of the regulation of the mosquito inducible NOS and the damage that nitrosative stress may cause to vector tissues is still rudimentary. Interestingly, the recently identified mosquito peroxiredoxin enzyme, A. stephensi 2-Cys peroxiredoxin (AsPrx-47830) has been shown to protect against stresses induced by NO, nitroxyl, peroxynitrite and hydrogen peroxide (Peterson and Luckhart, 2006). Peroxinitrite, for instance, is involved in reactions that cause DNA damage and nitration of proteins (see discussion in Peterson and Luckhart, 2006). Feeding on an uninfected blood meal was shown to induce an increase in AsPrx-47830 midgut expression from 2-20 h post blood meal with a higher level of induction being observed in $P$. berghei infected-mosquito midguts from $12 \cdot 5-48 \mathrm{~h}$ post blood meal (Peterson and Luckhart, 2006). It would thus appear that there may be measures in place to protect midgut cells from the potential cytotoxic effect of levels of nitric oxide generated as a result of the presence of an infected bloodmeal.

In addition to a general up-regulation of midgut NOS, levels of NOS expression that are detectable by immunostaining have been shown to specifically co-localise with invaded cells. This expression has been associated with the subsequent death by apoptosis of cells (Kumar et al. 2004). This apoptosis is thought to be initiated by nitric oxide, whose production is catalyzed by NOS activity in cells invaded by $P$. falciparum or P. berghei (Han et al. 2000; Luckhart et al. 1998). As discussed earlier, $\mathrm{NO}$ is one of the prime inducers of apoptosis and NO induced intracellular mechanisms result in the activation of caspases (Murphy, 1999).

Although titres of NO that are generated specifically in invaded cells could, in themselves, initiate the death of the cell, Kumar and colleagues (Kumar et al. 2004; Kumar and Barillas-Mury, 2005) propose that protein nitration may be involved in initiating apoptosis. They suggest that reactive nitrogen intermediates are produced that lead to protein nitration in some of the invaded cells, as detected by immunofluorescent staining of nitrotyrosine. Two different tyrosine nitration pathways have been proposed (Kumar et al. 2004; Kumar and 


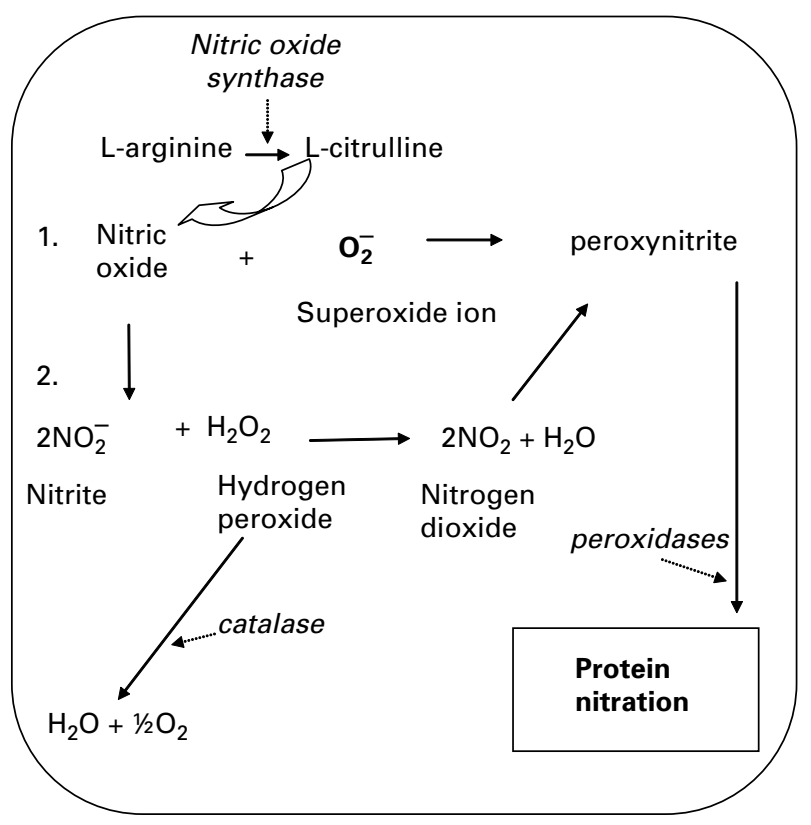

Fig. 3. Schematic of proposed reactions in a midgut cell invaded by an ookinete. Nitric oxide synthase catalyses the synthesis of nitric oxide. Superoxide ions are produced by the oxidation of oxygen. Peroxynitrite may be formed by one of two pathways $(1,2)$. Based on Kumar et al. (2004).

Barillas-Mury, 2005). In the classic pathway, NO reacts with superoxide ion to form peroxynitrite whilst the alternative pathway involves the initial conversion of NO to nitrite followed by its oxidation by peroxidases, in the presence of hydrogen peroxide, to nitrogen dioxide and eventual generation of peroxynitrite (Fig. 3). Inducible peroxidases were identified in $P$. berghei-infected $A$. stephensi that were gluteraldehyde, but not paraformaldehyde, resistant (Kumar et al. 2004) and high peroxidase activity was located in cells in advanced stages of apoptosis. Additionally, out of sixteen peroxidase genes, six were found to be differentially expressed in the midguts of $P$. berghei-infected $A$. gambiae, five were induced and the expression of the other one was reduced. Tyrosine nitration may inactivate proteins, particularly those with a tyrosine residue at the catalytic site (Alvarez and Radi, 2003), but a direct link between protein nitration and apoptosis in mosquito midgut epithelial cells has not been demonstrated. Although the work of Kumar and colleagues (Kumar et al. 2004) showed that peroxidase expression is associated with apoptosis in midgut cells, it did not demonstrate that protein nitration initiated cell death. Indeed, as nitration was only detected in cells in an advanced stage of apoptosis, it is unlikely to be a direct inducer of apoptosis. In addition, there is, as yet, no complete picture of the induction pathway for apoptosis. Neither all the intermediates in the classical nor the alternative pathways proposed by Kumar and co-workers were demonstrated to be up-regulated specifically in invaded cells.

Currently, we have no understanding of the biochemical pathways involved in controlling apoptosis in the infected-mosquito midgut. Anacaspase-7 is one of three apoptosis-related molecules that has been identified in cDNA libraries enriched for sequences expressed immediately after midgut invasion (Abraham et al. 2004). It shares $40 \%$ identity and $60 \%$ homology with the Drosophila caspase DECAY. Antibodies raised against Anacaspase-7 were used to recognise a putative proteolytic product that was only present in gut cells after invasion by large numbers of ookinetes, suggesting a dose-related activation of a caspase-related molecule (Abraham et al. 2004). Putative anti-apoptotic genes were expressed when oocysts were present (Srinivasan et al. 2004). Additionally, microarray analyses of the mosquito transcriptome at varying hours post infection have also detected upregulation of genes involved in apoptosis (Hall et al. 2005; Xu et al. 2005).

\section{INFECTION-INDUCED APOPTOSIS IN MOSQUITO OVARIES}

Plasmodium infection also results in apoptosis of cells in another epithelial layer, the follicular epithelium. These cells surround developing oocytes in the terminal follicle of each ovariole. Ingestion of a blood meal immediately initiates a gonotrophic cycle in anopheline mosquitoes. Yolk protein, or vitellogenin, is synthesised in the fat body and transported to the ovaries, where it is taken into developing oocytes by receptor mediated endocytosis. To gain access to the oolemma, vitellogenin must pass through the spaces that develop between the follicular epithelial cells. Provided the blood meal is large enough, all the terminal follicles in each ovary will produce an egg within about 50 hours. However, by $12 \mathrm{~h}$ post-feeding on an infected blood meal, patches of cells in the follicular epithelium of some of the ovarioles show characteristic signs of apoptosis. Staining with acridine orange and examination of ultrathin sections demonstrated nuclear condensation and DNA fragmentation was observed following a TUNEL assay (Hopwood et al. 2001). A comparison of ovaries from uninfected and Plasmodium yoelii nigeriensis-infected A. stephensi, at various times post-feeding, identified signs of apoptosis in 14-16\% of follicles from infected females but never more than $4 \%$ in uninfected ones (Hopwood et al. 2001). In A. gambiae ovaries, $P$. y. nigeriensis infection was associated with the activation of a caspase-like molecule that could be detected with FAM-VAD.fmk in approximately $25 \%$ of the ovarian follicles. Injection of the immune elicitor lipopolysaccharide or sephadex beads that stimulate melanisation also produced a significant 
increase in the number of follicles displaying caspase-like activity (Ahmed and Hurd, 2006). Follicle cell apoptosis resulted in the resorption of developing oocytes (Hopwood et al. 2001), thus smaller egg batches were produced by infected mosquitoes (reviewed in Hurd (2003)). Artificial induction of an immune response also caused fecundity reduction as a result of follicle resorption (Ahmed et al. 2002).

\section{Apoptotic pathways in the ovary}

Although we have identified caspase-like activity as important for the initiation of follicle resorption, we know nothing of the exact molecules involved in initiating or inhibiting apoptosis in the ovarian tissue of mosquitoes. In Drosophila, apoptosis occurs in response to both developmental and environmental signals. Whilst the death of nurse cells late in oogenesis is part of the normal developmental process, whole egg chambers, including follicle cells, undergo apoptosis in response to several triggers including a diet lacking protein or no transfer of male sex peptide during mating. The molecular genetics of this have been comprehensively summarised by McCall (McCall, 2004). Based on a variety of studies, a pathway for programmed cell death during mid-oogenesis was proposed that was initiated by insulin signalling-inhibited ecdysone signalling. It is suggested that a reduction in ecdysone signalling may act on the Apf-1 orthologue Dark, which activates an unknown initiator caspase. This, in turn, activates the effector caspase Dcp-1 which may be required to activate another effector caspase, Drice. Apoptosis activators such as reaper (rpr), head involution defective (hid) and (grim) are not required for germline apoptosis, however $r p r$ and hid-induced apoptotic death in follicle cells results in death of follicles before maturity (Chao and Nagoshi, 1999). Cytochrome $c$ is specifically expressed at late oogenesis and it is proposed that the initiator, Dredd, and other caspases may be involved at this stage (McCall, 2004).

Several caspases have been identified in the A. gambiae genome, and some of the Drosophila caspases have Anopheles orthologues (Christophides et al. 2002). These workers grouped the mosquito caspase S8 with the Drosophila S-prodomain caspase, $d c p 1$, and damm was most similar to Anopheles S9 and $\mathrm{S} 10$. The caspases dredd and dronc also have orthologues, but $r p r$ has not been identified in A. gambiae.

Peaks of expression of $A$. stephensi E517 caspase transcript and a bax-like inhibitor of apoptosis transcript occur in the midgut at $40 \mathrm{~h}$ and 14-20 d (Xu et al. 2005). In A. gambiae an analysis of transcriptome response to midgut invasion was examined by comparison with the transcriptome from mosquitoes fed a circumsporozoite and TRAP-related protein knockout (CTRPko) that develops in the midgut lumen but is unable to invade the epithelium. Five inhibitor-of-apoptosis protein (IAPs) were upregulated and one down-regulated during ookinete invasion. Three of these, together with viral IAPassociated factor, mapped to the major cytoskeleton clusters CL15 and CL12, together with the gene encoding the serpin SRPN10. There was also differential regulation of genes implicated in redox metabolism and detoxification included thioredoxin reductase, two thioredoxin peroxidases, a general peroxidase precursor and 3 glutathione-S-transferases (Vlachou et al. 2005).

Plasmodium does not come into direct contact with mosquito ovaries, so the induction of apoptosis and follicle resorption is not induced by invasion (as it is in the midgut) and must be triggered by external signals. Crampton and Luckhart noticed nonuniform expression of $A s 60 A$, a member of the TGF $\beta 1$ super-family (see above), in the developing eggs of infected A. stephensi at 24 h post blood meal. It is possible that this expression could up-regulate NOS, but expression of NOS in ovarian follicles has, so far, not been reported. Elevated levels of $\mathrm{NO}$ or RNIs in the haemolymph are associated with infection and must be considered as candidate triggers. Finally, an infection-induced change in endocrine status may mirror events that lead to apoptosis in Drosophila follicles, though no examination of ecdysteroid or juvenile hormone titres have been reported in infected insects to date.

\section{THE FUTURE}

Our knowledge of interactions that occur between malaria parasites and their mosquito vectors has expanded enormously during the past decade, and is continuing to do so. This has been assisted by the publication of the full genome sequence of A. gambiae, a major malaria vector in Africa (Holt et al. 2002) and a human malaria parasite, P. falciparum (Gardner et al. 2002). The availability of associated bioinformatics resources (Kriventseva et al. 2005) is aiding the burgeoning application of genomics, transcriptomics and proteomics to mapping the sporogonic cycle of Plasmodium and the response of the mosquito to infection. It is to be hoped that this wealth of data will, eventually, assist in the unravelling of the molecular pathways controlling apoptosis in parasite and host, though its immediate use is limited as homologues or orthologues of most apoptosis related genes in mammalian, C. elegans or Drosophila pathways are absent.

\section{ACKNOWLEDGEMENTS}

We are grateful for financial support from The Wellcome Trust (069162/Z/02/Z) and helpful comments on the manuscript made by J. Mottram and S. Luckhart. 
REFERENCES

Abraham, E. G., Islam, S., Srinivasan, P., Ghosh, A. K., Valenzuela, J. G., Ribeiro, J. M., Kafatos, F. C., Dimopoulos, G. and Jacobs-Lorena, M. (2004). Analysis of the Plasmodium and Anopheles transcriptional repertoire during ookinete development and midgut invasion. Fournal of Biological Chemistry 279, 5573-5580.

Abraham, E. G., Pinto, S. B., Ghosh, A., Vanlandingham, D. L., Budd, A., Higgs, S., Kafatos, F. C., Jacobs-Lorena, M. and Miche1, K. (2005). An immune-responsive serpin, SRPN6, mediates mosquito defense against malaria parasites. Proceedings of the National Academy of Sciences, USA 279, 5573-5580.

Ahmed, A. M., Baggott, S., Maingon, R. and Hurd, H. (2002). The costs of mounting an immune response are reflected in the reproductive fitness of Anopheles gambiae. Oikos 97, 371-377.

Ahmed, A. M. and Hurd, H. (2006). Immune stimulation and malaria infection impose reproductive costs in Anopheles gambiae via follicular apoptosis. Microbes and Infection 8, 308-315.

Alavi, Y., Arai, M., Mendoza, J., Tufet-Bayona, M., Sinha, R., Fowler, K., Billker, O., Franke-Fayard, B., Janse, C. J., Waters, A. and Sinden, R. E. (2003). The dynamics of interactions between Plasmodium and the mosquito: a study of the infectivity of Plasmodium berghei and Plasmodium gallinaceum, and their transmission by Anopheles stephensi, Anopheles gambiae and Aedes aegypti. International Fournal for Parasitology 33, 933-943.

Al-Olayan, E. M., Williams, G. T. and Hurd, H. (2002). Apoptosis in the malaria protozoan, Plasmodium berghei: a possible mechanism for limiting intensity of infection in the mosquito. International Fournal for Parasitology 32, 1133-1143.

Alvarez, B. and Radi, R. (2003). Peroxynitrite reactivity with amino acids and proteins. Amino Acids 25, 295-311.

Atamna, H. and Ginsburg, H. (1993). Origin of reactive oxygen species in erythrocytes infected with Plasmodium falciparum. Molecular and Biochemical Parasitology 61, 231-241.

Bai, P., Bakondi, E., Szabo, E., Gergely, P., Szabo, C. and Virag, L. (2001). Partial protection by poly(ADP-ribose) polymerase inhibitors from nitroxyl-induced cytotoxity in thymocytes. Free Radical Biology and Medicine 31, 1616-1623.

Balmer, P., Phillips, H. M., Maestre, A. E., McMonagle, F. A. and Phillips, R. S. (2000). The effect of nitric oxide on the growth of Plasmodium falciparum, $P$. chabaudi and $P$. berghei in vitro. Parasite Immunology 22, 97-106.

Barrett, A. J. and Rawlings, N. D. (2001). Evolutionary lines of cysteine peptidases. Biological Chemistry 382, $727-733$.

Baton, L. A. and Ranford-Cartwright, L. C. (2004). Plasmodium falciparum ookinete invasion of the midgut epithelium of Anopheles stephensi is consistent with the Time Bomb model. Parasitology 129, 663-676.

Baton, L. A. and Ranford-Cartwright, L. C. (2005a). How do malaria ookinetes cross the mosquito midgut wall? Trends in Parasitology 21, 22-28.
Baton, L. A. and Ranford-Cartwright, L. C. (2005b). Spreading the seeds of million-murdering death: metamorphoses of malaria in the mosquito. Trends in Parasitology 21, 573-580.

Blandin, S. and Levashina, E. A. (2004). Mosquito immune responses against malaria parasites. Current Opinion in Immunology 16, 16-20.

Blomgren, K., Zhu, C., Wang, X., Karlsson, J. O., Leverin, A. L., Bahr, B. A., Mallard, C. and Hagberg, H. (2001). Synergistic activation of caspase-3 by $\mathrm{m}$-calpain after neonatal hypoxia-ischemia: a mechanism of "pathological apoptosis"? Fournal of Biological Chemistry 276, 10191-10198.

Bozdech, Z., Zhu, J., Joachimiak, M. P., Cohen, F. E., Pulliam, B. and DeRisi, J. L. (2003). Expression profiling of the schizont and trophozoite stages of Plasmodium falciparum with a long-oligonucleotide microarray. Genome Biology 4, R9 Epub.

Bursch, W. (2001). The autophagosomal-lysosomal compartment in programmed cell death. Cell Death and Differentiation 8, 569-581.

Chao, S. and Nagoshi, R. N. (1999). Induction of apoptosis in the germline and follicle layer of Drosophila egg chambers. Mechanisms of Development 88, 159-172.

Christophides, G. K., Zdobnov, E., Barillas-Mury, C., Birney, E., Blandin, S., Blass, C., Brey, P. T., Collins, F. H., Danielli, A., Dimopoulos, G., Hetru, C., Hoa, N. T., Hoffmann, J. A., Kanzok, S. M., Letunic, I., Levashina, E. A., Loukeris, T. G., Lycett, G., Meister, S., Michel, K., Moita, L. F., Muller, H. M., Osta, M. A., Paskewitz, S. M., Reichhart, J. M., Rzhetsky, A., Troxler, L., Vernick, K. D., Vlachou, D., Volz, J., von Mering, C., Xu, J., Zheng, L., Bork, P. and Kafatos, F. C. (2002). Immunity-related genes and gene families in Anopheles gambiae. Science 298, 159-165.

Clark, I. A., Rockett, K. A. and Burgner, D. (2003). Genes, nitric oxide and malaria in African children. Trends in Parasitology 19, 335-337.

Collins, F. H., Sakai, R. K., Vernick, K. D., Paskewitz, S., Seeley, D. C., Miller, L. H., Collins, W. E., Campbell, C. C. and Gwadz, R. W. (1986). Genetic selection of a Plasmodium-refractory strain of the malaria vector Anopheles gambiae. Science 234, 607-610.

Crampton, A. and Luckhart, S. (2001). The role of As60A, a TGF-beta homolog, in Anopheles stephensi innate immunity and defense against Plasmodium infection. Infection Genetics and Evolution 1, 131-141.

Danielli, A., Barillas-Mury, C., Kumar, S., Kafatos, F. C. and Loukeris, T. G. (2005). Overexpression and altered nucleocytoplasmic distribution of Anopheles ovalbumin-like SRPN10 serpins in Plasmodium-infected midgut cells. Cellular Microbiology 7, 181-190.

Deponte, M. and Becker, K. (2004). Plasmodium falciparum - do killers commit suicide? Trends in Parasitology 20, 165-169.

Dimopoulos, G. (2003). Insect immunity and its implication in mosquito-malaria interactions. Cell Microbiology 5, 3-14.

Eksi, S., Czesny, B., Greenbaum, D. C., Bogyo, M. and Williamson, K. C. (2004). Targeted disruption of Plasmodium falciparum cysteine protease, falcipain 1, 
reduces oocyst production, not erythrocytic stage growth. Molecular Microbiology 53, 243-250.

Fox, B. A. and Bzik, D. J. (1994). Analysis of stage-specific transcripts of the Plasmodium falciparum serine repeat antigen (SERA) gene and transcription from the SERA locus. Molecular and Biochemical Parasitology 68, 133-144.

Gamboa de Dominguez, N. D. and Rosenthal, P. J. (1996). Cysteine proteinase inhibitors block early steps in hemoglobin degradation by cultured malaria parasites. Blood 87, 4448-4454.

Gardner, M. J., Hall, N., Fung, E., White, O., Berriman, M., Hyman, R. W., Carlton, J. M., Pain, A., Nelson, K. E., Bowman, S., Paulsen, I. T., James, K., Eisen, J. A., Rutherford, K., Salzberg, S. L., Craig, A., Kyes, S., Chan, M. S., Nene, V., Shallom, S. J., Suh, B., Peterson, J., Angiuoli, S., Pertea, M., Allen, J., Selengut, J., Haft, D., Mather, M. W., Vaidya, A. B., Martin, D. M., Fairlamb, A. H., Fraunholz, M. J., Roos, D. S., Ralph, S. A., McFadden, G. I., Cummings, L. M., Subramanian, G. M., Mungall, C., Venter, J. C., Carucci, D. J., Hoffman, S. L., Newbold, C., Davis, R. W., Fraser, C. M. and Barrell, B. (2002). Genome sequence of the human malaria parasite Plasmodium falciparum. Nature 419, 498-511.

Ghosh, A., Edwards, M. J. and Jacobs-Lorena, M. (2000). The journey of the malaria parasite in the mosquito: hopes for the new century. Parasitology Today 16, 196-201

Goh, S. L., Goh, L. L. and Sim, T. S. (2005). Cysteine protease falcipain 1 in Plasmodium falciparum is biochemically distinct from its isozymes. Parasitology Research 97, 295-301.

Gor, D. O., Li, A. C., Wiser, M. F. and Rosenthal, P. J. (1998). Plasmodial serine repeat antigen homologues with properties of schizont cysteine proteases. Molecular and Biochemical Parasitology 95, 153-158.

Gupta, L., Kumar, S., Han, Y. S., Pimenta, P. F. and Barillas-Mury, C. (2005). Midgut epithelial responses of different mosquito-Plasmodium combinations: the actin cone zipper repair mechanism in Aedes aegypti. Proceedings of the National Academy of Sciences, USA 102, 4010-4015

Hall, N., Karras, M., Raine, J. D., Carlton, J. M., Kooij, T. W., Berriman, M., Florens, L., Janssen, C. S., Pain, A., Christophides, G. K., James, K., Rutherford, K., Harris, B., Harris, D., Churcher, C., Quail, M. A., Ormond, D., Doggett, J., Trueman, H. E., Mendoza, J., Bidwell, S. L., Rajandream, M. A., Carucci, D. J., Yates, J. R., 3rd, Kafatos, F. C., Janse, C. J., Barrell, B., Turner, C. M., Waters, A. P. and Sinden, R. E. (2005). A comprehensive survey of the Plasmodium life cycle by genomic, transcriptomic, and proteomic analyses. Science 307, 82-86.

Han, Y. S. and Barillas-Mury, C. (2002). Implications of Time Bomb model of ookinete invasion of midgut cells. Insect Biochemistry and Molecular Biology 32, 1311-1316.

Han, Y. S., Thompson, J., Kafatos, F. C. and Barillas-Mury, C. (2000). Molecular interactions between Anopheles stephensi midgut cells and Plasmodium berghei: the time bomb theory of ookinete invasion of mosquitoes. The EMBO Fournal 19, 6030-6040.

Harada, M., Owhashi, M., Suguri, S., Kumatori, A., Nakamura, M., Kanbara, H., Matsuoka, H. and Ishii, A. (2001). Superoxide-dependent and -independent pathways are involved in the transmission blocking of malaria. Parasitology Research 87, 605-608.

Herrera-Ortiz, A., Lanz-Mendoza, H., Martinez-Barnetche, J., Hernandez-Martinez, S., Villarreal-Trevino, C., Aguilar-Marcelino, L. and Rodriguez, M. H. (2004). Plasmodium berghei ookinetes induce nitric oxide production in Anopheles pseudopunctipennis midguts cultured in vitro. Insect Biochemistry and Molecular Biology 34, 893-901.

Hodder, A. N., Drew, D. R., Epa, V. C., Delorenzi, M., Bourgon, R., Miller, S. K., Moritz, R. L., Frecklington, D. F., Simpson, R. J., Speed, T. P., Pike, R. N. and Crabb, B. S. (2003). Enzymic, phylogenetic, and structural characterization of the unusual papain-like protease domain of Plasmodium falciparum SERA5. Fournal of Biological Chemistry 278, 48169-48177.

Holt, R. A., Subramanian, G. M., Halpern, A., Sutton, G. G., Charlab, R., Nusskern, D. R., Wincker, P., Clark, A. G., Ribeiro, J. M., Wides, R., Salzberg, S. L., Loftus, B., Yandell, M., Majoros, W. H., Rusch, D. B., Lai, Z., Kraft, C. L., Abril, J. F., Anthouard, V., Arensburger, P., Atkinson, P. W., Baden, H., de Berardinis, V., Baldwin, D., Benes, V., Biedler, J., Blass, C., Bolanos, R., Boscus, D., Barnstead, M., Cai, S., Center, A., Chaturverdi, K., Christophides, G. K., Chrystal, M. A., Clamp, M., Cravchik, A., Curwen, V., Dana, A., Delcher, A., Dew, I., Evans, C. A., Flanigan, M., GrundschoberFreimoser, A., Friedli, L., Gu, Z., Guan, P., Guigo, R., Hillenmeyer, M. E., Hladun, S. L., Hogan, J. R., Hong, Y. S., Hoover, J., Jaillon, O., Ke, Z., Kodira, C., Kokoza, E., Koutsos, A., Letunic, I., Levitsky, A., Liang, Y., Lin, J. J., Lobo, N. F., Lopez, J. R., Malek, J. A., McIntosh, T. C., Meister, S., Miller, J., Mobarry, C., Mongin, E., Murphy, S. D., O’Brochta, D. A., Pfannkoch, C., Qi, R., Regier, M. A., Remington, K., Shao, H., Sharakhova, M. V., Sitter, C. D., Shetty, J., Smith, T. J., Strong, R., Sun, J., Thomasova, D., Ton, L. Q., Topalis, P., Tu, Z., Unger, M. F., Walenz, B., Wang, A., Wang, J., Wang, M., Wang, X., Woodford, K. J., Wortman, J. R., Wu, M., Yao, A., Zdobnov, E. M., Zhang, H., Zhao, Q., Zhao, S., Zhu, S. C., Zhimulev, I., Coluzzi, M., della Torre, A., Roth, C. W., Louis, C., Kalush, F., Mural, R. J., Myers, E. W., Adams, M. D., Smith, H. O., Broder, S., Gardner, M. J., Fraser, C. M., Birney, E., Bork, P., Brey, P. T., Venter, J. C., Weissenbach, J., Kafatos, F. C., Collins, F. H. and Hoffman, S. L. (2002). The genome sequence of the malaria mosquito Anopheles gambiae. Science 298, 129-149.

Hopwood, J. A., Ahmed, A. M., Polwart, A., Williams, G. T. and Hurd, H. (2001). Malaria-induced apoptosis in mosquito ovaries: a mechanism to control vector egg production. Fournal of Experimental Biology 204, 2773-2780. 
Hurd, H. (2003). Manipulation of medically important insect vectors by their parasites. Annual Review of Entomology 48, 141-161.

Hurd, H. and Carter, V. (2004). The role of programmed cell death in Plasmodium-mosquito interactions. International Fournal for Parasitology 34, 1459-1472.

Hurd, H., Carter, V. and Nacer, A. (2005). Interactions between malaria and mosquitoes: the role of apoptosis in parasite establishment and vector response to infection. Current Topics in Microbiology and Immunology 289, 185-217.

Hurd, H., Taylor, P., Adams, D., Underhill, A. and Eggleston, P. (2006). Evaluating the costs of mosquito resistance to malaria. Evolution 59, 2560-2572.

Kiefer, M. C., Crawford, K. A., Boley, L. J., Landsberg, K. E., Gibson, H. L., Kaslow, D. C. and Barr, P. J. (1996). Identification and cloning of a locus of serine repeat antigen (sera)-related genes from Plasmodium vivax. Molecular and Biochemical Parasitology 78, 55-65.

Kriventseva, E. V., Koutsos, A. C., Blass, C., Kafatos, F. C., Christophides, G. K. and Zdobnov, E. M. (2005). AnoEST: toward A. gambiae functional genomics. Genome Research 15, 893-899.

Kumar, S. and Barillas-Mury, C. (2005). Ookineteinduced midgut peroxidases detonate the time bomb in anopheline mosquitoes. Insect Biochemistry and Molecular Biology 35, 721-727.

Kumar, S., Gupta, L., Han, Y. S. and Barillas-Mury, C. (2004). Inducible peroxidases mediate nitration of anopheles midgut cells undergoing apoptosis in response to Plasmodium invasion. Fournal of Biological Chemistry 279, 53475-53482.

Lanz-Mendoza, H., Hernandez-Martinez, S., Ku-Lopez, M., Rodriguez Mdel, C., Herrera-Ortiz, A. and Rodriguez, M. H. (2002). Superoxide anion in Anopheles albimanus hemolymph and midgut is toxic to Plasmodium berghei ookinetes. Fournal of Parasitology 88, 702-706.

Le Roch, K. G., Zhou, Y., Blair, P. L., Grainger, M., Moch, J. K., Haynes, J. D., De La Vega, P., Holder, A. A., Batalov, S., Carucci, D. J. and Winzeler, E. A. (2003). Discovery of gene function by expression profiling of the malaria parasite life cycle. Science 301, 1503-1508.

Lensen, A., Mulder, L., Tchuinkam, T., Willemsen, L., Eling, W. and Sauerwein, R. (1998). Mechanisms that reduce transmission of Plasmodium falciparum malaria in semiimmune and nonimmune persons. Fournal of Infectious Disease 177, 1358-1363.

Lim, J., Gowda, D. C., Krishnegowda, G. and Luckhart, S. (2005). Induction of nitric oxide synthase in Anopheles stephensi by Plasmodium falciparum: mechanism of signaling and the role of parasite glycosylphosphatidylinositols. Infection and Immunity 73, 2778-2789.

Luckhart, S., Crampton, A. L., Zamora, R., Lieber, M. J., Dos Santos, P. C., Peterson, T. M., Emmith, N., Lim, J., Wink, D. A. and Vodovotz, Y. (2003). Mammalian transforming growth factor beta1 activated after ingestion by Anopheles stephensi modulates mosquito immunity. Infection and Immunity 71, 3000-3009.
Luckhart, S., Vodovotz, Y., Cui, L. and Rosenberg, R. (1998). The mosquito Anopheles stephensi limits malaria parasite development with inducible synthesis of nitric oxide. Proceedings of the National Academy of Sciences, USA 95, 5700-5705.

Madeo, F., Herker, E., Maldener, C., Wissing, S., Lachelt, S., Herlan, M., Fehr, M., Lauber, K., Sigrist, S. J., Wesselborg, S. and Frohlich, K. U. (2002). A caspase-related protease regulates apoptosis in yeast. Molecular Cell 9, 911-917.

Mazzoni, C., Herker, E., Palermo, V., Jungwirth, H., Eisenberg, T., Madeo, F. and Falcone, C. (2005). Yeast caspase 1 links messenger RNA stability to apoptosis in yeast. EMBO Reports 6, 1076-1081.

McCall, K. (2004). Eggs over easy: cell death in the Drosophila ovary. Developmental Biology 274, 3-14.

McIntosh, M. T., Elliott, D. A. and Joiner, K. A. (2005). Plasmodium falciparum: discovery of peroxidase active organelles. Experimental Parasitology 111, 133-136.

Miche1, K. and Kafatos, F. C. (2005). Mosquito immunity against Plasmodium. Insect Biochemistry and Molecular Biology 35, 677-689.

Miller, S. K., Good, R. T., Drew, D. R., Delorenzi, M., Sanders, P. R., Hodder, A. N., Speed, T. P., Cowman, A. F., Koning-ward, T. F. and Crabb, B. S. (2002). A subset of Plasmodium falciparum SERA genes are expressed and appear to play an important role in the erythrocytic cycle. Fournal of Biological Chemistry 277, 47524-47532.

Motard, A., Landau, I., Nussler, A., Grau, G., Baccam, D., Mazier, D. and Targett, G. A. (1993). The role of reactive nitrogen intermediates in modulation of gametocyte infectivity of rodent malaria parasites. Parasite Immunology 15, 21-26.

Mottram, J. C., Helms, M. J., Coombs, G. H. and Sajid, M. (2003). Clan CD cysteine peptidases of parasitic protozoa. Trends in Parasitology 19, 182-187.

Müller, S. (2004). Redox and antioxidant systems of the malaria parasite Plasmodium falciparum. Molecular Microbiology 53, 1291-1305.

Murphy, M. P. (1999). Nitric oxide and cell death. Biochimica et Biophysica Acta 1411, 401-414.

Nakagawa, T. and Yuan, J. (2000). Cross-talk between two cysteine protease families. Activation of caspase-12 by calpain in apoptosis. Fournal of Cell Biology 150, 887-894.

Naotunne, T. S., Karunaweera, N. D., Mendis, K. N. and Carter, R. (1993). Cytokine-mediated inactivation of malarial gametocytes is dependent on the presence of white blood cells and involves reactive nitrogen intermediates. Immunology $\mathbf{7 8}$, 555-562.

Osta, M. A., Christophides, G. K. and Kafatos, F. C. (2004a). Effects of mosquito genes on Plasmodium development. Science 303, 2030-2032.

Osta, M. A., Christophides, G. K., Vlachou, D. and Kafatos, F. C. (2004b). Innate immunity in the malaria vector Anopheles gambiae: comparative and functional genomics. Fournal of Experimental Biology 207, 2551-2563.

Pang, X. L., Mitamura, T. and Horii, T. (1999). Antibodies reactive with the $\mathrm{N}$-terminal domain of Plasmodium falciparum serine repeat antigen inhibit 
cell proliferation by agglutinating merozoites and schizonts. Infection and Immunity 67, 1821-1827.

Peterson, T. m. L. and Luckhart, S. (2006). A mosquito 2-Cys peroxiredoxin protects against nitrosative and oxidative stresses associated with malaria parasite infection. Free Radical Biology and Medicine 40, 1067-1082.

Picot, S., Burnod, J., Bracchi, V., Chumpitazi, B. f. F. and Ambroise-Thomas, P. (1997). Apoptosis related to chloroquine sensitivity of the human malaria parasite Plasmodium falciparum. Transactions of the Royal Society of Tropical Medicine and Hygiene 91, 590-591.

Richman, A. M., Dimopoulos, G., Seeley, D. and Kafatos, F. C. (1997). Plasmodium activates the innate immune response of Anopheles gambiae mosquitoes. EMBO Fournal 16, 6114-6119.

Rockett, K. A., Awburn, M. M., Cowden, W. B. and Clark, I. A. (1991). Killing of Plasmodium falciparum in vitro by nitric oxide derivatives. Infection and Immunity 59, 3280-3283.

Rosenthal, P. J. (1995). Plasmodium falciparum: effects of proteinase inhibitors on globin hydrolysis by cultured malaria parasites. Experimental Parasitology 80, 272-281.

Rosenthal, P. J. (2004). Cysteine proteases of malaria parasites. International fournal for Parasitology 34, 1489-1499.

Rosenthal, P. J., Olson, J. E., Lee, G. K., Palmer, J. T., Klaus, J. L. and Rasnick, D. (1996). Antimalarial effects of vinyl sulfone cysteine proteinase inhibitors. Antimicrobial Agents and Chemotherapy 40, 1600-1603.

Rosenthal, P. J., Sijwali, P. S., Singh, A. and Shenai, B. R. (2002). Cysteine proteases of malaria parasites: targets for chemotherapy. Current Pharmaceutical Design 8, 1659-1672.

Rozman-Pungercar, J., Kopitar-Jerala, N., Bogyo, M., Turk, D., Vasiljeva, O., Stefe, I., Vandenabeele, P., Bromme, D., Puizdar, V., Fonovic, M., Trstenjak-Prebanda, M., Dolenc, I., Turk, V. and Turk, B. (2003). Inhibition of papain-like cysteine proteases and legumain by caspase-specific inhibitors: when reaction mechanism is more important than specificity. Cell Death and Differentiation 10, 881-888.

Sinden, R. E. (2002). Molecular interactions between Plasmodium and its insect vectors. Cellular Microbiology 4, 713-724.

Sinden, R. E., Alavi, Y. and Raine, J. D. (2004). Mosquito-malaria interactions: a reappraisal of the concepts of susceptibility and refractoriness. Insect Biochemistry and Molecular Biology 34, 625-629.

Sobolewski, P., Gramaglia, I., Frangos, J., Intaglietta, M. and van der Heyde, H. C. (2005). Nitric oxide bioavailability in malaria. Trends in Parasitology 21, 415-422.

Squier, M. K. and Cohen, J. J. (1997). Calpain, an upstream regulator of thymocyte apoptosis. Fournal of Immunology 158, 3690-3697.

Squier, M. K., Miller, A. C., Malkinson, A. M. and Cohen, J. J. (1994). Calpain activation in apoptosis. Fournal of Cell Physiology 159, 229-237.

Srinivasan, P., Abraham, E. G., Ghosh, A. K., Valenzuela, J., Ribeiro, J. M., Dimopoulos, G.,
Kafatos, F. C., Adams, J. H., Fujioka, H. and Jacobs-Lorena, M. (2004). Analysis of the Plasmodium and Anopheles transcriptomes during oocyst differentiation. Fournal of Biological Chemistry 279, 5581-5587.

Stoka, V., Turk, B., Schendel, S. L., Kim, T. H., Cirman, T., Snipas, S. J., Ellerby, L. M., Bredesen, D., Freeze, H., Abrahamson, M., Bromme, D., Krajewski, S., Reed, J. C., Yin, X. M., Turk, V. and Salvesen, G. S. (2001). Lysosomal protease pathways to apoptosis. Cleavage of bid, not pro-caspases, is the most likely route. Fournal of Biological Chemistry 276, 3149-3157.

Tachado, S. D., Gerold, P., McConville, M. J., Baldwin, T., Quilici, D., Schwarz, R. T. and Schofield, L. (1996). Glycosylphosphatidylinositol toxin of Plasmodium induces nitric oxide synthase expression in macrophages and vascular endothelial cells by a protein tyrosine kinase-dependent and protein kinase $\mathrm{C}$-dependent signaling pathway. Fournal of Immunology 156, 1897-1907.

Thornberry, N. A. (1997). The caspase family of cysteine proteases. British Medical Bulletin 53, 478-490.

Thornberry, N. A., Rano, T. A., Peterson, E. P., Rasper, D. M., Timkey, T., Garcia-Calvo, M., Houtzager, V. M., Nordstrom, P. A., Roy, S., Vaillancourt, J. P., Chapman, K. T. and Nicholson, D. W. (1997). A combinatorial approach defines specificities of members of the caspase family and granzyme B. Functional relationships established for key mediators of apoptosis. Fournal of Biological Chemistry 272, 17907-17911.

Toler, S. (2005). The plasmodial apicoplast was retained under evolutionary selective pressure to assuage blood oxidative stress. Medical Hypothesis 65, 683-690.

Turk, B., Stoka, V., Rozman-Pungercar, J., Cirman, T., Droga-Mazovec, G., Oresic, K. and Turk, V. (2002). Apoptotic pathways: involvement of lysosomal proteases. Biological Chemistry 383, 1035-1044.

Uren, A. G., O'Rourke, K., Aravind, L., Pisabarro, M. T., Seshagiri, S., Koonin, E. V. and Dixit, V. M. (2000). Identification of paracaspases and metacaspases: two ancient families of caspase-like proteins, one of which plays a key role in MALT lymphoma. Molecular Cell 6, 961-967.

Vaughan, J. A., Hensley, L. and Beier, J. C. (1994a). Sporogonic development of Plasmodium yoelii in five anopheline species. Fournal of Parasitology 80, 674-681.

Vaughan, J. A., Noden, B. H. and Beier, J. C. (1994b). Sporogonic development of cultured Plasmodium falciparum in six species of laboratory-reared Anopheles mosquitoes. American Fournal of Tropical Medicine and Hygiene 51, 233-243.

Vernick, K. D., Fujioka, H., Seeley, D. C., Tandler, B., Aikawa, M. and Miller, L. H. (1995). Plasmodium gallinaceum: a refractory mechanism of ookinete killing in the mosquito, Anopheles gambiae. Experimental Parasitology 80, 583-595.

Vlachou, D. and Kafatos, F. C. (2005). The complex interplay between mosquito positive and negative regulators of Plasmodium development. Current Opinion in Microbiology 8, 415-421.

Vlachou, D., Schlegelmilch, T., Christophides, G. K. and Kafatos, F. C. (2005). Functional genomic analysis 
of midgut epithelial responses in Anopheles during Plasmodium invasion. Current Biology 15, 1185-1195.

Vlachou, D., Zimmermann, T., Cantera, R., Janse, C. J., Waters, A. P. and Kafatos, F. C. (2004).

Real-time, in vivo analysis of malaria ookinete locomotion and mosquito midgut invasion. Cellular Microbiology 6, 671-685.

Waterhouse, N. J., Finucane, D. M., Green, D. R., Elce, J. S., Kumar, S., Alnemri, E. S., Litwack, G., Khanna, K., Lavin, M. F. and Watters, D. J. (1998). Calpain activation is upstream of caspases in radiationinduced apoptosis. Cell Death and Differentiation 5, 1051-1061.

Whitten, M. m. A., Shiao, S. H. and Levashina, E. A. (2006). Mosquito midguts and malaria: cell biology, compartmentalization and immunology. Parasite Immunology 28, 121-130.

Wolf, B. B., Schuler, M., Echeverri, F. and Green, D. R. (1999). Caspase-3 is the primary activator of apoptotic DNA fragmentation via DNA fragmentation factor-45/inhibitor of caspase-activated DNase inactivation. Fournal of Biological Chemistry 274, 30651-30656.

Wu, Y., Wang, X., Liu, X. and Wang, Y. (2003). Data-mining approaches reveal hidden families of proteases in the genome of malaria parasite. Genome Research 13, 601-616.
Xu, X., Dong, Y., Abraham, E. G., Kocan, A., Srinivasan, P., Ghosh, A. K., Sinden, R. E., Ribeiro, J. M., Jacobs-Lorena, M., Kafatos, F. C. and Dimopoulos, G. (2005). Transcriptome analysis of Anopheles stephensi-Plasmodium berghei interactions. Molecular and Biochemical Parasitology 142, 76-87.

Zheng, L., Wang, S., Romans, P., Zhao, H., Luna, C. and Benedict, M. Q. (2003). Quantitative trait loci in Anopheles gambiae controlling the encapsulation response against Plasmodium cynomolgi Ceylon. BMC Genetics 4, 16. Oct 24; 4, 16: http://www. biomedcentral.com/1471-2156/4/16.

Zhu, J., Krishnegowda, G. and Gowda, D. C. (2005). Induction of proinflammatory responses in macrophages by the glycosylphosphatidylinositols of Plasmodium falciparum: the requirement of extracellular signal-regulated kinase, p38, c-Jun $\mathrm{N}$-terminal kinase and NF-kappaB pathways for the expression of proinflammatory cytokines and nitric oxide. Fournal of Biological Chemistry 280, 8617-8627.

Zieler, H. and Dvorak, J. A. (2000). Invasion in vitro of mosquito midgut cells by the malaria parasite proceeds by a conserved mechanism and results in death of the invaded midgut cells. Proceedings of the National Academy of Sciences, USA 97, 11516-11521. 